\section{Plan to grow more cannabis for research turned down}

US researchers do not need a second federally approved facility for providing research-grade cannabis, the Drug Enforcement Administration (DEA) has ruled. The decision ends an eight-year bid by Lyle Craker at the University of Massachusetts in Amherst, to grow cannabis for medical research, which was supported by the Multidisciplinary Association for Psychedelic Studies (MAPS). A single laboratory at the University of Mississippi supplies cannabis under a contract with the National Institute of Drug Addiction.

Craker, MAPS and others have argued that the current supply of cannabis is of inconsistent quality, difficult to obtain, and that efforts to widen that supply are being stalled for political reasons (see Nature 430, 492; 2004). In 2007, a DEA judge recommended that Craker's application to set up a second facility should be granted; but the DEA's final ruling, made on 7 January, said the current supply was adequate.

\section{FDA to regulate the use of transgenic animals}

The US Food and Drug Administration (FDA) has adopted guidelines for regulating genetically engineered animals.

Released on 15 January, the rules have been more than a decade in the making. They follow a set of draft guidelines, released in September 2008, which drew fire for effectively treating genetically engineered animals as drugs (see Nature 456, 2; 2008).

In response to other concerns about the transparency of the approval process, the new guidelines note that the agency intends to hold public advisory committee meetings before approving any genetically engineered animals.

Earlier this month, an FDA advisory committee deemed an anti-clotting drug called ATryn, produced in the milk of genetically engineered goats, to be safe an important step towards the eventual

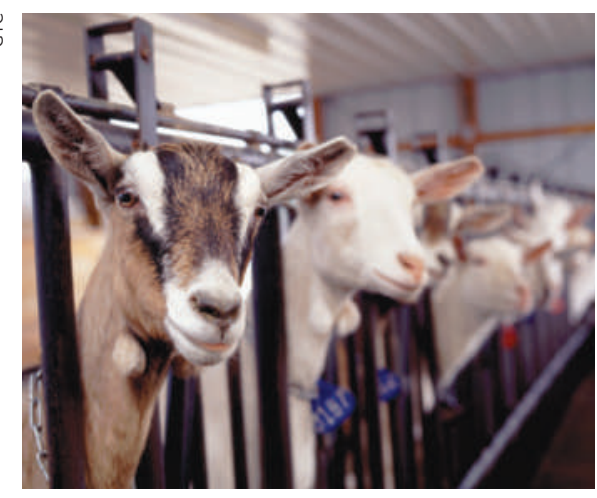

Goats: drug factories of the future?

\title{
Europe set to clamp down on pesticide use
}

After three years of wrangling, the European Union (EU) is expected next month to finally approve controversial legislation to regulate pesticide use. Early drafts of the law drew protest from manufacturers, farmers and scientists, who claimed that a drastic reduction in the number of available pesticides would lower crop yields and raise food prices.

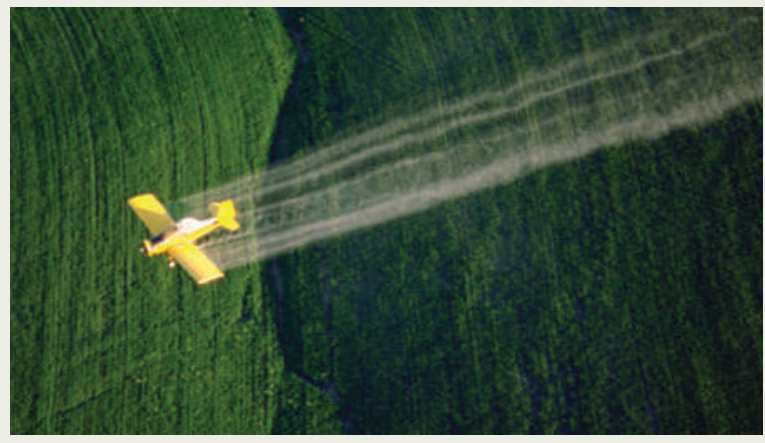

The compromise ruling backed last week by the European Parliament will result in just 23 of the roughly 500 marketed pesticides being banned, according to the Swedish Chemicals Agency.

The directive also promotes the use of non-chemical pest-control methods, bans aerial crop spraying without authorization and curbs pesticide use in areas such as parks and playgrounds. Once approved, the ruling must be incorporated into the national laws of all member states by 2011. For a longer version of this story, see: http://tinyurl.com/7d6zvt.

approval of the drug for sale in US markets. For a longer version of this story, see http://tinyurl. com/8kv5dr.

\section{Polio eradication battle is bolstered by $\$ 630$ million}

A final push to overcome the few remaining pockets of polio infection in the world is being supported by grants totalling US\$630 million from the Bill \& Melinda Gates Foundation, the humanitarian group Rotary International, and the UK and German governments.

The funding, announced on 21 January, will support the World Health Organization's Global Polio Eradication Initiative, which involves vaccinating billions of children. Since its launch in 1988, the effort has cut the annual polio toll from 350,000 cases in 125 countries to just 1,600 cases last year. If the crippling disease could be eradicated, it would become the second disease, after smallpox, to be officially wiped out.

Reservoirs of polio now remain in four countries where the disease is endemic: Nigeria, where polio vaccines were opposed following false rumours that they carried HIV and caused female infertility; India, where vaccine effectiveness has been hampered by poor sanitation and high population density; and conflict zones in Afghanistan and Pakistan.

For a longer version of this story, see http://tinyurl. com/7e5s4u.

\section{Democrats hasten action on climate legislation}

Democrats in the US House of Representatives have announced plans to draw up climate legislation this spring, arguing that business leaders need regulatory certainty to drive a green economic recovery. Incoming Energy and Commerce Chairman Henry Waxman, who held his first climate hearing on 15 January, said that the committee would deliver the legislation by the end of May, a decision backed by House Speaker Nancy Pelosi. Although President Obama favours a domestic capand-trade programme, many energy and climate analysts expected that the legislation would be delayed as lawmakers focus on the economy and a less controversial bill to advance clean energy.

The US Climate Action Partnership, a coalition of major industrial firms and environmental organizations, bolstered Waxman's case by calling for legislation that would curb carbon dioxide emissions by $42 \%$ by 2030 and $80 \%$ by mid-century compared with 2005 levels.

\section{Billion-dollar neutron facility gets thumbs up}

The US Department of Energy has approved a US\$1-billion upgrade to the Spallation Neutron Source (SNS) at Oak Ridge National Laboratory in Tennessee.

The SNS generates neutrons by firing a high-energy beam of protons at a mercury target. The neutrons are used to probe the structures of materials ranging from proteins to superconducting ceramics. The existing SNS facility, completed in 2006, currently feeds neutrons to 10 instruments used by about 1,000 scientists and engineers last year. The addition of a second target will allow for up to 24 more instruments, fed by long pulses of slower-moving cold neutrons, which can be used to study larger molecules such as polymers.

Conceptual design work on the upgrade can now begin, with construction expected to finish no earlier than 2020 . 